\title{
On the selection and design of proteins and peptide derivatives for the production of photoluminescent, red-emitting gold quantum clusters
}

\author{
Balázs Söptei • Lívia Naszályi Nagy • Péter Baranyai • \\ Ildikó Szabó • Gábor Mező • Ferenc Hudecz • Attila Bóta \\ Published online: 1 August 2013 \\ (C) The Author(s) 2013. This article is published with open access at SpringerLink.com
}

\begin{abstract}
Novel pathways of the synthesis of photoluminescent gold quantum clusters (AuQCs) using biomolecules as reactants provide biocompatible products for biological imaging techniques. In order to rationalize the rules for the preparation of red-emitting AuQCs in aqueous phase using proteins or peptides, the role of different organic structural units was investigated. Three systems were studied: proteins, peptides, and amino acid mixtures, respectively. We have found that cysteine and tyrosine are indispensable residues. The SH/S-S ratio in a single molecule is not a critical factor in the synthesis, but on the other hand, the stoichiometry of cysteine residues and the gold precursor is crucial. These observations indicate the importance of proper chemical behavior of all species in a wide size range extending from the atomic distances (in the $\mathrm{Au}^{\mathrm{I}}-\mathrm{S}$ semi ring) to nanometer distances covering the larger sizes of proteins assuring the hierarchical structure of the whole self-assembled system.
\end{abstract}

Electronic supplementary material The online version of this article (doi:10.1007/s13404-013-0100-2) contains supplementary material, which is available to authorized users.

B. Söptei · L. Naszályi Nagy • A. Bóta $(\bowtie)$

Department of Biological Nanochemistry, Institute of Molecular

Pharmacology, Research Centre for Natural Sciences,

Hungarian Academy of Sciences, 59-67. Pusztaszeri road,

Budapest 1025, Hungary

e-mail: bota.attila@ttk.mta.hu

\section{P. Baranyai}

Department of Spectroscopy, Institute of Molecular Pharmacology,

Research Centre for Natural Sciences, Hungarian Academy of

Sciences, 59-67. Pusztaszeri road, Budapest 1025, Hungary

I. Szabó · G. Mező • F. Hudecz

Research Group of Peptide Chemistry, Hungarian Academy of

Sciences, Eötvös Loránd University, Pázmány Péter stny 1/A,

Budapest 1117, Hungary

F. Hudecz

Department of Organic Chemistry, Eötvös Loránd University, Budapest112 POB 32, 1518, Hungary
Keywords Gold clusters · Photoluminescence · Proteins · Peptides

\section{Introduction}

The field of photoluminescent noble metal clusters is a hot topic in materials science [1]. Subnanometer-sized gold particles show photoluminescence emission that can be tuned in a wide range of the spectrum, from ultraviolet through visible to the near infrared [2]. These clusters show good photostability compared to organic fluorophores [3]. Furthermore, unlike semiconductor quantum dots [4], gold clusters do not have the disadvantage of susceptibility to oxidation.

Gold quantum clusters (AuQCs) can be prepared in a variety of ways. A main strategy for preparation is a top-down approach in which gold clusters are prepared by controlled etching of monolayer-protected gold nanoparticles [5-8]. A ligand exchange-based reaction has also been reported [9]. Bottom-up techniques are also known; polyvinylpyrrolidone [10] and polyamidoamine dendrimers are suitable protective agents for cluster production [2]. In the latter two methods, sodium borohydride is used for the reduction of $\mathrm{Au}^{\mathrm{III}}$. Photoluminescent metal clusters with small ligands are already applied for cellular imaging $[5,11,12]$.

Alternative bottom-up methods are being developed for cluster preparation: recently, some water-soluble proteins (will be referred to as active clustering proteins, ACPs) have been reported to react with $\mathrm{HAuCl}_{4}$ to produce red-emitting AuQCs in situ in aqueous phase, acting as reducing and complexing/ protecting agents [13]. These are bovine serum albumin (BSA), trypsin, pepsin, horseradish peroxidase, lactoferrin, human serum transferrin, lysozyme, and cellular retinoic acid-binding protein 2 (CRABP2) [14-21]. Proteinconjugated gold clusters are already applied as analytical sensors of $\mathrm{Hg}^{2+}, \mathrm{Pb}^{2+}, \mathrm{Cu}^{2+}$ ions, and glutathione [15, 21-24]. Precursors used in protein-based techniques are nontoxic; 
moreover, BSA-protected clusters do not show significant toxicity in vitro [25], which allows their application in biological systems. In the future, expansion of the protein-directed production methods can be expected.

Although there is a growing number of detailed works in the field of protein-mediated AuQC preparation, it is yet unclear which physicochemical characteristics of proteins are crucial in cluster formation, and there are no general criteria for protein selection in the literature. Furthermore, the design of peptides for the synthesis of gold nanoparticles has been elaborated [26], but there is no such work in the literature for AuQC production.

In an earlier study, cysteine and tyrosine residues were claimed to be responsible for the cluster forming activity of proteins [14], but there is a lack of experimental evidence for this theory. Nevertheless, investigation on the oxidation state of gold suggested that $\mathrm{Au}^{\mathrm{I}}$ and $\mathrm{Au}^{0}$ could be both present in the clusters [14-16, 18], which implicates that different residues are involved in the process. It has been demonstrated that cysteine is not the only amino acid by which $\mathrm{Au}^{\mathrm{I}}$ species can be formed: methionine can also reduce gold salts in a similar manner [27, 28]. Tryptophan, having a similar redox character to that of tyrosine at high $\mathrm{pH}$ values [29], has been found to be the strongest reducing amino acid for $\mathrm{Au}^{\mathrm{III}}$ in its free form and also as a peptide residue for gold nanoparticle synthesis [26]. Tyrosine, on the other hand, could be essential, since it could reduce $\mathrm{Au}^{\mathrm{III}}$ to unstable $\mathrm{Au}^{\mathrm{II}}$ species [30], which can be an important step in the reaction. Moreover, cysteine has been reported to facilitate the formation of $\mathrm{Au}^{\mathrm{I}}$ thiolate polymers [31], which are responsible for the attractive forces in clusters through aurophilic interaction [32-35].

Peptides can also be used for cluster preparation. Insulin, for example, has been shown to produce AuQCs for cellular imaging [36]. The simplest templating peptide is glutathione ( $\gamma$-GluCys-Gly), which can effectively stabilize subnanometer clusters if an external reducing agent is also used (note that glutathione itself cannot reduce $\mathrm{Au}^{\text {III }}$ to produce $\mathrm{Au}^{0}$ ) [7, 33]. Glutathioneprotected clusters, however, have low photoluminescence quantum yield compared to that of protein-coated clusters [37], which is a disadvantage in imaging techniques. In the literature, AuQC synthesizing activity of peptides has not been widely investigated. To date, only a single artificial peptide (CCYRGRKKRRQRRR) has been designed especially for AuQC production [3].

Another key aspect is the concentration of the protein necessary for the reaction. It has been confirmed that redemitting $\mathrm{Au}_{25}$ clusters consist of a 13-atom core, surrounded by 12 peripheral gold atoms forming an $\mathrm{Au}^{\mathrm{I}}-\mathrm{S}$ semi ring [38-40]. The existence of the latter requires a minimum number of sulfur-containing residues per gold cluster [39, 41]. These considerations suggest the existence of a critical initial molar ratio of the protein and the gold precursor necessary for cluster formation. Although it has been observed that cluster formation takes place if the concentration of the protein is relatively high [14, 18, 21], such critical initial molar ratio has not yet been defined in the literature.

In our study, we intended to identify the criteria that determine cluster-producing feature of proteins and peptides. We considered the following questions: (1) Is the presence of cysteine and tyrosine in a protein or peptide sufficient? (2) If cysteine and tyrosine do have a key role in cluster production, can either of them be replaced with residues of similar character? (3) Do ACPs show similar motifs in primary structure? (4) Can AuQCs be prepared using sulfur-containing and reducing amino acids in their free form, without the use of an external reducing agent? Experiments have been performed using amino acid mixtures, peptides, and proteins, respectively. Furthermore, sequences of ACPs have been analyzed.

Three systems were studied: proteins, peptides, and amino acid mixtures, respectively. In the case of protein-mediated AuQC production experiments, we have chosen commercially available proteins in a molecular weight range of 30 to $70 \mathrm{kDa}$. BSA, porcine trypsin, bovine hyaluronidase- 3 , and concanavalin A were selected in order to clarify if protein properties (number of cysteine residues per molecule, percentage of disulfide-bonded cysteine residues) affect their efficiency in cluster formation. Furthermore, hyaluronidase-3 is a watersoluble protein with sulfur-containing and reducing residues, and its cluster-producing feature has not been investigated earlier. Since known ACPs show diversity in the secondary and tertiary structure, we proposed that cluster-producing activity of proteins is determined mainly by their amino acid profile and/or primary structure. Sequence of all proteins used in our experiments and ACPs in the literature have been analyzed to study the function of the primary structure in cluster formation.

Peptides have been designed for our experiments to elucidate if either cysteine or tyrosine can be substituted in the reaction (cysteine with methionine and tyrosine with tryptophan) and to clarify if the position of cysteine residues affects cluster formation. Gonadotropin-releasing hormone derivatives as potential drug-targeting moieties suitable for targeted cancer therapy and cancer detection were also chosen to these studies [42]. These compounds contain cysteines with free thiol group or in disulfide bridge, as well as both tyrosine and tryptophan.

For our experiments with amino acid mixtures, we have chosen sulfur-containing and strong reducing amino acids, proposing that their presence is sufficient for cluster formation. It has been reported that the former can protect clusters and form $\mathrm{Au}^{\mathrm{I}}$ complexes [28, 37-41], while the latter can produce $\mathrm{Au}^{0}[14,26,29]$. We designed our mixtures based on the assumption that tyrosine and cysteine play the key role in the process [14], but also investigated the possibility of synergic effects with tryptophan and methionine. Mixtures of W-M and W-C have not been studied, since they have been found inefficient in $\mathrm{Au}^{\mathrm{III}}$ reduction earlier in the literature [26]. 
In this paper, we specified certain crucial parameters whereby an easy selection or design of an appropriate host biomolecule and the adjustment of the precursor concentration for the green production of photoluminescent gold clusters will be possible.

\section{Experimental}

Materials

Gold(III) chloride hydrate, $99.999 \%$, was purchased from Aldrich. BSA ( $\geq 98 \%$ ), bovine hyaluronidase-3 (H3), concanavalin A (cA), porcine trypsin, L-tyrosine $(\geq 99.0 \%)$, Lmethionine (99.0-101.0\%), L-cystine ( $\geq 99.5 \%)$, and D,Ldithiotreitol ( $\geq 99.0 \%)$ were ordered from Sigma. L-cysteine (99 \%) and L-tryptophan (99\%) were obtained from Alfa Aesar. Phosphate-buffered saline tablets (for buffer solutions of $\mathrm{pH}$ 7.4) were purchased from Fluka. Sodium hydroxide solution (1 M), analytical grade, was purchased from Carlo Erba. Model peptides $\mathrm{CCYE}_{6} \mathrm{R}_{3}, \mathrm{CCWE}_{6} \mathrm{R}_{3}$, and $\mathrm{MMYE}_{6} \mathrm{R}_{3}$ ( $99 \%$ ) were ordered from GenScript. Model GnRH peptide derivatives, with $>95 \%$, were prepared at the Research Group of Peptide Chemistry at Eötvös Loránd University, Budapest (see Online Resource 1). Deionized water of Millipore purity $(18.2 \mathrm{M} \Omega \mathrm{cm})$ was used for all experiments.

\section{Production of AuQCs with proteins}

Four different proteins were used in the experiments, properties of which are summarized in Table 1. Protein-coated gold clusters were prepared based on previously reported methods $[14,15]$. Briefly, aqueous solutions of the proteins ( $25 \mathrm{mg} \mathrm{mL}^{-1}$ for BSA, $40 \mathrm{mg} \mathrm{mL}^{-1}$ for trypsin, $50 \mathrm{mg} \mathrm{mL}^{-1}$ for hyaluronidase- 3 , and $100 \mathrm{mg} \mathrm{mL}^{-1}$ for $\mathrm{cA}$, respectively) were made. Aliquots were then mixed with equal volume of $\mathrm{HAuCl}_{4}$ solution $\left(10^{-2} \mathrm{M}\right)$. After $10 \mathrm{~min}$ of stirring, $1 \mathrm{M}$ $\mathrm{NaOH}$ solution (5\% of the original mixture in volume) was injected to set the $\mathrm{pH}$ to 12.0 . Mixtures were reacted at $40{ }^{\circ} \mathrm{C}$ overnight. Products were stored in the refrigerator at $5{ }^{\circ} \mathrm{C}$.

In the case of proteins, we defined a critical molar ratio, $\phi_{c}$, which is the lowest protein/gold ratio in the reaction by which photoluminescent gold clusters form. In order to determine $\phi_{\mathrm{c}}$ for $\mathrm{H} 3$, the concentration of $\mathrm{HAuCl}_{4}$ was kept constant $\left(5 \cdot 10^{-3} \mathrm{M}\right)$, experiments were carried out at protein/gold molar ratios of $0.180,0.090$, and 0.045 , respectively. We proposed that reactions with ratios below $\phi_{\mathrm{c}}$ result in the formation of nanoparticles similarly as reported earlier for other proteins $[14,21]$. We estimated $\phi_{\mathrm{c}}$ considering the lowest protein concentration yielding photoluminescent clusters and compared our results with data extracted from the literature.

Preparation of AuQCs with peptides

Amino acid sequences of the peptides used in our experiments are shown in Table 2. The concentration of peptides in the reaction was constant $\left(3.6 \cdot 10^{-4} \mathrm{M}\right)$, peptide/gold ratio was adjusted to 1.00 . In the case of $\mathrm{CCYE}_{6} \mathrm{R}_{3}$, a peptide gold ratio of 0.36 was also tested. All experiments were carried out at $\mathrm{pH}$ 12.0 , at $40^{\circ} \mathrm{C}$, stirring the mixtures overnight.

AuQC production experiments with amino acid mixtures

$\mathrm{HAuCl}_{4}$ was reacted with mixtures of different amino acids to clarify if free amino acids can produce gold quantum clusters. Concentrations and ratios of different amino acids were adjusted to mimic the BSA-mediated synthesis (Table 3). In these experiments, $\mathrm{NaOH}$ was added prior to the addition of the $\mathrm{HAuCl}_{4}$ solution $\left(10^{-2} \mathrm{M}\right.$, equal volume to that of the amino acid solution) to dissolve nonpolar amino acids (tyrosine, methionine, and tryptophan) efficiently at $\mathrm{pH} 12.0$. Analogous experiments have also been carried out using Lcystine in the mixtures.

\section{Characterization techniques}

Samples containing proteins and free amino acids were diluted with phosphate-buffered saline $(\mathrm{pH}=7.4, \mathrm{SI}=162.7 \mathrm{mM}$ ) to ten times of their original volume. The $\mathrm{pH}$ of the mixtures was measured with a Jenway $3540 \mathrm{pH}$ meter. Mixtures containing peptides were studied undiluted in order to achieve sufficient signal-to-noise ratio in photoluminescence (PL) measurements. Steady-state PL spectra have been collected using a Shimadzu RFPC 3501 fluorimeter. Samples were excited at $350 \mathrm{~nm}$, excitation and emission slits of $5 \mathrm{~nm}$ were used. We detected the presence of AuQCs by measuring spectral properties of the reaction products.

It is well known that the luminescence lifetime red-emitting gold clusters is in the range of microseconds [37, 38, 43];
Table 1 Properties of proteins used in AuQC production experiments

\begin{tabular}{llclc}
\hline Protein & Mass [kDa] & Isoelectric point & $\begin{array}{l}\text { Number of cysteine } \\
\text { residues per molecule }\end{array}$ & $\begin{array}{l}\text { Number of disulfide } \\
\text { bonds per molecule }\end{array}$ \\
\hline BSA & 66.4 & 4.7 & 35 & 17 \\
Trypsin & 23.5 & 10.5 & 12 & 6 \\
Hyaluronidase-3 & 14.0 & 5.4 & 4 & 0 \\
Concanavalin A & 26.0 & 5.0 & 0 & 0 \\
\hline
\end{tabular}


Table 2 Amino acid sequence of peptides and peptide dimers used in Au quantum cluster synthesis experiments

\begin{tabular}{|c|c|c|c|}
\hline Peptide name & Amino acid sequence & Mass (Da) & Isoelectric point $\mathrm{t}^{\mathrm{a}}$ \\
\hline $\mathrm{CCYE}_{6} \mathrm{R}_{3}$ & $\mathrm{H}_{2} \mathrm{~N}$-Cys-Cys-Tyr-Glu-Glu-Glu-Glu-Glu-Glu-Arg-Arg-Arg-COOH & 1,631 & 4.25 \\
\hline $\mathrm{CCWE}_{6} \mathrm{R}_{3}$ & $\mathrm{H}_{2} \mathrm{~N}$-Cys-Cys-Trp-Glu-Glu-Glu-Glu-Glu-Glu-Arg-Arg-Arg-COOH & 1,654 & 4.25 \\
\hline $\mathrm{MMYE}_{6} \mathrm{R}_{3}$ & $\mathrm{H}_{2} \mathrm{~N}-\mathrm{Met}-\mathrm{Met}-\mathrm{Tyr}-\mathrm{Glu}-\mathrm{Glu}-\mathrm{Glu}-\mathrm{Glu}-\mathrm{Glu}-\mathrm{Glu}$-Arg-Arg-Arg-COOH & 1,687 & 4.25 \\
\hline$\left[\mathrm{D}-\mathrm{Lys}^{6}(\mathrm{Cys})\right]-\mathrm{GnRH}-\mathrm{I}$ & Glp-His-Trp-Ser-Tyr-D-Lys(Cys)-Leu-Arg-Pro-Gly-COHN 2 & 1,357 & 9.16 \\
\hline$\left(\left[\mathrm{D}-\mathrm{Lys}^{6}(\mathrm{Cys})\right]-\mathrm{GnRH}-\mathrm{I}\right)_{2}$ & (Glp-His-Trp-Ser-Tyr-D-Lys(Cys)-Leu-Arg-Pro-Gly-COHN $\left.{ }_{2}\right)_{2}$ & 2,711 & 9.16 \\
\hline$\left[\mathrm{D}-\mathrm{Lys}^{6}(\mathrm{Ac}-\mathrm{Cys})\right]-\mathrm{GnRH}-\mathrm{I}$ & Glp-His-Trp-Ser-Tyr-D-Lys(Ac-Cys)-Leu-Arg-Pro-Gly-CONH 2 & 1,399 & 9.16 \\
\hline$\left(\left[\mathrm{D}-\mathrm{Lys}^{6}(\mathrm{Ac}-\mathrm{Cys})\right]-\mathrm{GnRH}-\mathrm{I}\right)_{2}$ & (Glp-His-Trp-Ser-Tyr-D-Lys(Ac-Cys)-Leu-Arg-Pro-Gly-CONH$\left.{ }_{2}\right)_{2}$ & 2,795 & 9.16 \\
\hline$\left[\mathrm{D}-\mathrm{Cys}^{6}\right]-\mathrm{GnRH}-\mathrm{II}$ & Glp-His-Trp-Ser-His-D-Cys-Trp-Tyr-Pro-Gly-CONH 2 & 1,282 & 7.32 \\
\hline$\left(\left[\mathrm{D}-\mathrm{Cys}{ }^{6}\right]-\mathrm{GnRH}-\mathrm{II}\right)_{2}$ & (Glp-His-Trp-Ser-His-D-Cys-Trp-Tyr-Pro-Gly-CONH$\left.{ }_{2}\right)_{2}$ & 2,563 & 7.32 \\
\hline
\end{tabular}

${ }^{\text {a }}$ Isoelectric point values were predicted using Innovagen Peptide Property Calculator (http://innovagen.se/custom-peptide-synthesis/peptide-propertycalculator/peptide-property-calculator.asp)

therefore, our samples showing red emission have been characterized by measuring luminescence lifetimes to confirm the presence of gold clusters. Time-resolved photoluminescence (TRPL) measurements have been carried out using an Edinburgh Instruments FLSP920 luminescence lifetime spectrometer. The excitation light source was an EPL-470 diode laser (473 nm; pulse duration, 140 ps at FWHM) and the detector was a Hamamatsu R3809U-50 microchannel plate photomultiplier. Decay curves were analyzed by nonlinear least-squares fitting method using Edinburgh F900 software. UV-visible absorbance spectra were obtained with a ThermoSpectronic Unicam UV500 spectrophotometer. Structural changes of proteins were followed by Fourier transform infrared (FTIR) spectroscopy, by observing the shifts of amide I and amide II bands. FTIR-attentuated total reflectance (ATR) spectra have been collected using a Varian FTS-2000 FTIR Spectrophotometer with a Golden Gate ATR head.

\section{Comparison of ACP structures}

Protein sequences were obtained from the UniProt database (https://www.uniprot.org), amino acid profile of all proteins can be found in Table 6 (see Appendix). Sequences were aligned by the Needleman-Wunsch algorithm using an online alignment tool (http://www.ebi.ac.uk/Tools/psa/emboss_needle). The BLOSUM60 matrix was applied for the calculation of scores.
The score of the alignment of human transferrin and bovine lactoferrin was used as a reference value, since these proteins are structural analogues (https://www.uniprot.org).

\section{Results and discussion}

\section{Production of AuQCs with proteins}

In order to determine which criteria are crucial in the case of proteins to make them efficient in cluster production, we investigated sequences of known ACPs. We have found that primary structures of ACPs do not have any ubiquitous sequential motif (see Online Resource 2). This suggested that clustering efficiency of a protein is not determined by specific motifs in its sequence, but the presence of certain residues is crucial. Considering the amino acid profiles of the investigated proteins (Table 3, Appendix), it is also apparent that there are ACPs that have no histidine (CRABP2), methionine (insulin), or tryptophan (egg white lysozyme) residues, which suggests that the presence of these amino acids is not essential in cluster formation. However, tyrosine and cysteine residues are present in the primary structure of all ACPs.

Steady-state PL emission spectra of reaction mixtures of $\mathrm{HAuCl}_{4}$ and $\mathrm{H} 3$, and $\mathrm{cA}$, are shown in Fig. 1. According to PL measurements, three of the selected proteins (BSA, trypsin,

Table 3 Composition of amino acid mixtures used in gold cluster production experiments

\begin{tabular}{|c|c|c|c|c|c|}
\hline \multicolumn{2}{|l|}{ Mixture 1} & \multicolumn{2}{|l|}{ Mixture 2} & \multicolumn{2}{|l|}{ Mixture 3} \\
\hline Component & Concentration $[\mathrm{M}]$ & Component & Concentration [M] & Component & Concentration $[\mathrm{M}]$ \\
\hline L-Cysteine & $2.6 \cdot 10^{-2}$ & L-Cysteine & $2.6 \cdot 10^{-2}$ & L-Cysteine & $2.6 \cdot 10^{-2}$ \\
\hline \multirow[t]{3}{*}{ L-Tyrosine } & $1.4 \cdot 10^{-2}$ & L-Tyrosine & $1.4 \cdot 10^{-2}$ & L-Tyrosine & $1.4 \cdot 10^{-2}$ \\
\hline & & L-Methionine & $3.0 \cdot 10^{-3}$ & L-Methionine & $3.0 \cdot 10^{-3}$ \\
\hline & & & & L-Tryptophan & $2.3 \cdot 10^{-3}$ \\
\hline
\end{tabular}




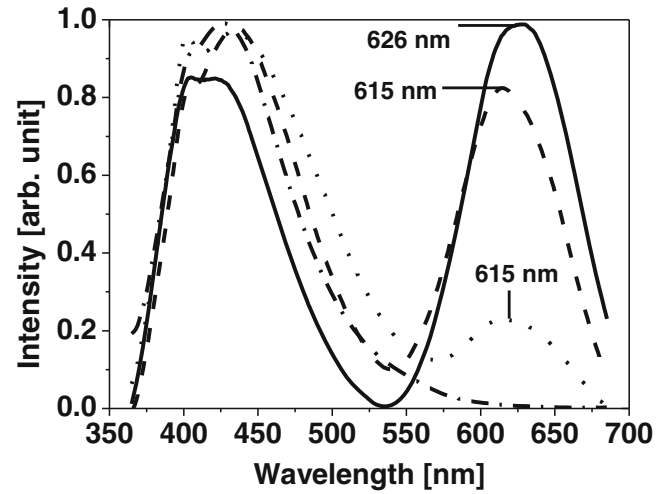

Fig. 1 Emission spectra of reaction products of $\mathrm{HAuCl}_{4}$ with protein: BSA (solid line), bovine hyaluronidase-3 (dashed line), porcine trypsin (dotted line), and concanavalin A (dash-dot line), respectively (an excitation wavelength of $350 \mathrm{~nm}$ was used)

and hyaluronidase-3) efficiently produced AuQCs, while concanavalin $\mathrm{A}$, the one with no cysteine residues, was found to be inactive in cluster synthesis. BSA- and trypsin-coated clusters showed similar emission properties to those earlier reported in the literature $[14,15]$.

$\mathrm{H} 3$-protected AuQCs showed an emission peak at $615 \mathrm{~nm}$. Red emission was not detected in the case $\mathrm{cA}$, and no nanoparticle formation was observed either. Emission lifetimes of samples with red emission have been measured; two lifetime components ( 0.9 and 2.3-2.4 $\mu \mathrm{s})$ were observed. Results of TRPL measurements in case of products prepared using proteins are summarized in Table 4.

As lifetimes of microsecond range are characteristic for thiolic ligand-protected gold clusters [37, 38, 43], these lifetime values indicate cluster formation unambiguously. TRPL results thus provided evidence that $\mathrm{H} 3$ is also an ACP. Since BSA, trypsin, and H3 have different $\mathrm{SH} /$ disulfide ratios, as shown in Table 1 , we can conclude that cysteine can be effective in thiol and also in disulfide form. In the case of porcine trypsin, however, we measured low emission intensity, probably due to autolysis of the enzyme.

In the case of H3, different protein/gold ratios were used in AuQC preparation experiments. We hypothesized that the value of $\phi_{\mathrm{c}}$ is solely determined by the number of cysteine residues in a protein, considering a stoichiometry of 18 thiol groups and 25 gold atoms $[39,40]$. Based on this assumption, the value of the critical ratio must be in inverse relation to the

Table 4 Emission lifetime values $(\tau)$ and pre-exponential constants $(\alpha)$ of red-emitting AuQCs produced using proteins

\begin{tabular}{lllll}
\hline Sample $^{\mathrm{a}}$ & $\tau_{1}[\mu \mathrm{s}]$ & $\alpha_{1}$ & $\tau_{2}[\mu \mathrm{s}]$ & $\alpha_{2}$ \\
\hline AuQC-BSA & 0.9 & 0.30 & 2.4 & 0.70 \\
AuQC-trypsin & 0.9 & 0.30 & 2.3 & 0.70 \\
AuQC-H3 & 0.9 & 0.33 & 2.3 & 0.67 \\
\hline
\end{tabular}

number of cysteine residues in a single molecule.

$\phi_{\mathrm{c}} \approx \frac{0.72}{n_{\mathrm{Cys}}}$

where $n_{\text {Cys }}$ is the number of cysteine residues in a single molecule. We supposed that $\phi_{\mathrm{c}}$ can be estimated by lowering the concentration of protein in the reaction mixture while keeping the concentration of $\mathrm{HAuCl}_{4}$ constant.

We observed that the concentration of $\mathrm{H} 3$ is a key factor in AuQC synthesis. UV-visible absorbance and PL spectra of the synthesis mixtures of $\mathrm{H} 3$ and $\mathrm{HAuCl}_{4}$ are shown in Fig. 2.

Results show that the nature of the reaction products does depend on the protein/gold ratio in the case of H3; nanoparticles or clusters can form depending on the synthetic conditions. At lower protein/gold ratios, non-fluorescent nanoparticles formed, plasmon absorption peaks of which were observed in the UV-Visible absorbance spectra. To compare our experimental results with data extracted from the literature $[14,18,21]$, we plotted the estimated $\phi_{c}$ values
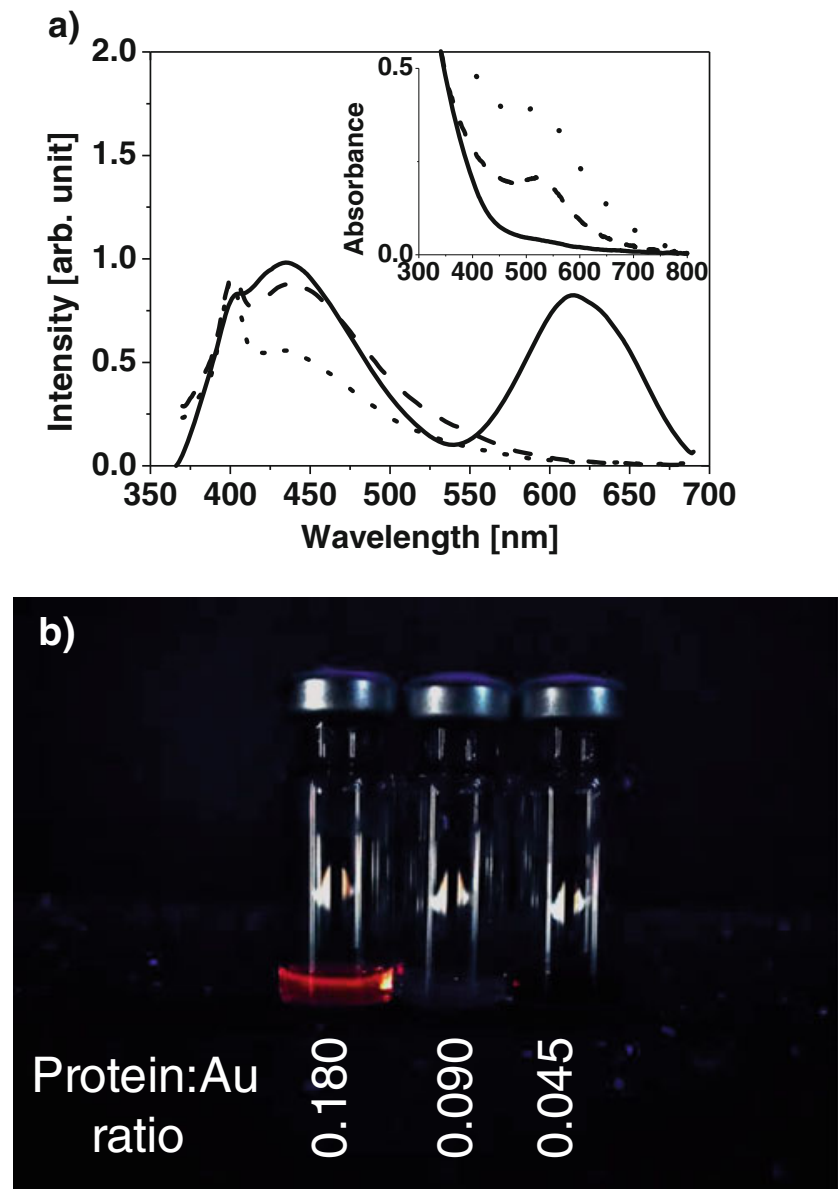

Fig. 2 a Emission spectra of reaction products of $\mathrm{H} 3$ and $\mathrm{HAuCl}_{4}$ with protein/gold ratios of 0.180 (solid line), 0.090 (dashed line), and 0.045 (dotted line), respectively (an excitation wavelength of $350 \mathrm{~nm}$ was used); inset shows UV-vis absorbance spectra of the samples; $\mathbf{b}$ photograph of samples taken under UV lamp (365 nm) 
for different proteins, and the theoretical values calculated based on the cysteine content of the proteins (using Eq. 1) are demonstrated in Fig. 3. Theoretically predicted values of $\phi_{\mathrm{c}}$ for proteins using the $\mathrm{Au}_{25} \mathrm{SR}_{18}$ stoichiometry in the calculation $[39,40]$ and experimentally estimated values proved to be coherent, indicating that $\phi_{\mathrm{c}}$ is in inverse ratio to the number of cysteine residues in a protein. Moreover, we found that disulfide-bonded and free cysteine residues can be considered as equivalent.

Preparation of AuQCs with peptides

In the case of model peptides (Table 2), $\mathrm{CCYE}_{6} \mathrm{R}_{3}$, [D-Cys ${ }^{6}$ GnRH-II, and ([D-Cys $\left.\left.{ }^{6}\right]-G n R H-I I\right)_{2}$ produced AuQCs in case of peptide/gold molar ratio of 1:1. PL spectra of reaction mixtures are shown in Fig. 4.

As in the case of proteins, emission lifetimes of redemitting samples have been measured, except for $\left[\mathrm{D}-\mathrm{Cys}^{6}\right]$ GnRH-II disulfide, since the reaction product formed an insoluble precipitate. Emission lifetimes of our samples with red emission are demonstrated in Table 5.

Microsecond lifetimes have been observed in the case of the reaction mixtures using model peptides as reactants, confirming the formation of AuQCs. Replacement of cysteine with methionine led to the inefficiency of the peptide. We observed the same effect when tyrosine was replaced by tryptophan. These results revealed that cysteine and tyrosine are exclusively responsible for cluster formation and cannot be substituted by other residues, which is an experimental evidence for earlier assumptions [3, 14]. Cysteine might be essential in cluster formation due to the electron withdrawing effect of the thiol-gold bond, which plays a crucial role in cluster stabilization [44]. If $\mathrm{CCWE}_{6} \mathrm{R}_{3}$ was used as a reactant, addition of 1 molar equivalent of free tyrosine or $\mathrm{MMYE}_{6} \mathrm{R}_{3}$ to the mixture did not facilitate the formation of AuQCs, emphasizing the importance of intramolecular processes in

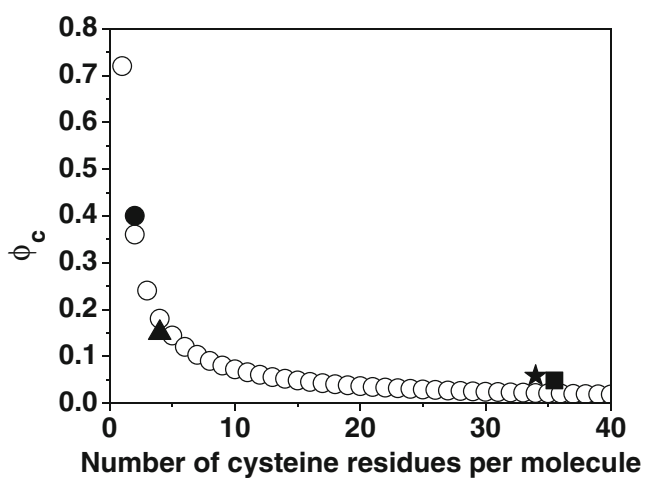

Fig. 3 Theoretical $\phi_{\mathrm{c}}$ values calculated from the number of cysteine residues in a single molecule (Eq. 1) (blank circles) and estimated $\phi_{\mathrm{c}}$ values for different proteins (solid circles): bovine hyaluronidase-3 (solid circle, based on our measurements), BSA (star [14]), bovine lactoferrin (square [18]), and egg white lysozyme (triangle [21]), respectively

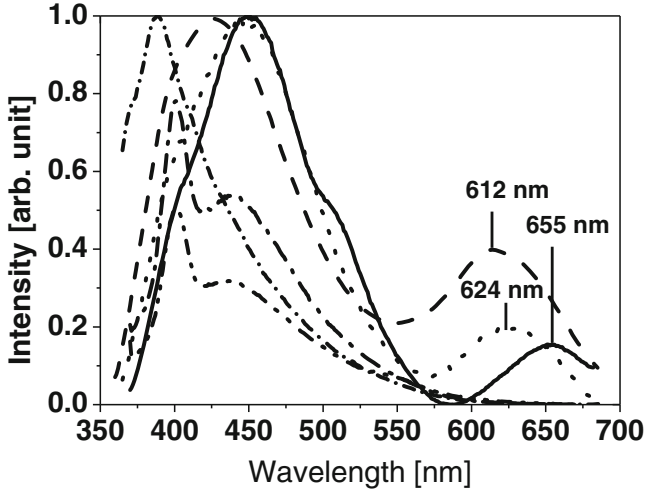

Fig. 4 Emission spectra of reaction products of $\mathrm{HAuCl}_{4}$ with $\mathrm{CCYE}_{6} \mathrm{R}_{3}$ (solid line), $\mathrm{CCWE}_{6} \mathrm{R}_{3}$ (dash-dot line), $\mathrm{MMYR}_{6} \mathrm{R}_{3}$ (dash-dot-dot line), [D-Lys $\left.{ }^{6}(\mathrm{Cys})\right]-G n R H-I$ (short dash-dot line), [D-Cys $\left.{ }^{6}\right]-G n R H-I I$ (dashed line), and ([D-Cys $\left.\left.{ }^{6}\right]-\mathrm{GnRH}-\mathrm{II}\right)_{2}$ (dotted line), respectively (an excitation wavelength of $350 \mathrm{~nm}$ was used)

the cluster formation reaction. Cluster synthesizing potency of $\left[\mathrm{D}-\mathrm{Cys}^{6}\right]-\mathrm{GnRH}-\mathrm{II}$ and $\left(\left[\mathrm{D}-\mathrm{Cys}^{6}\right]-\mathrm{GnRH}-\mathrm{II}\right)_{2}$ showed that non-terminal cysteine residues are active. On the other hand, the inefficiency of [D-Lys $\left.{ }^{6}(\mathrm{Cys})\right]-\mathrm{GnRH}-\mathrm{I}$, [D-Lys $^{6}$ (Ac-Cys)]GnRH-I, and their disulfide dimers indicated that the position of Cys residues is a crucial factor in AuQC production. There was no difference in cluster formation using acetylated or nonacetylated versions of GnRH-I derivatives. For this reason, we can conclude that the free amino group on the terminal cysteine is not the key factor in prevention of AuQC production. We presume that our conclusions for peptides are also valid for proteins.

FTIR spectra of the reaction products prepared using proteins and peptides

FTIR-ATR spectra and the corresponding second derivative spectra, demonstrated in Fig. 5, show shifts of the amide I and amide II bands to higher wavenumbers in the case of red-emitting samples compared to native proteins.

In the spectra of the negative controls, cA and [DLys ${ }^{6}$ (Ac-Cys)]-GnRH-I, shifts of the corresponding bands were negligible. Shifts of the amide bands are due to conformational changes of the biomolecules, as it has been demonstrated earlier [44]. These results indicated that the proteins go through conformational changes during the reaction, which are associated with

Table 5 Emission lifetime values $(\tau)$ and pre-exponential constants $(\alpha)$ of red-emitting AuQCs produced using peptides

\begin{tabular}{lllll}
\hline Sample & $\tau_{1}[\mu \mathrm{s}]$ & $\alpha_{1}$ & $\tau_{2}[\mu \mathrm{s}]$ & $\alpha_{2}$ \\
\hline AuQC-CCYE $6 \mathrm{R}_{3}$ & 0.4 & 0.33 & 1.3 & 0.67 \\
AuQC-[D-Cys ${ }^{6}$ ]-GnRH-II & 1.1 & 0.43 & 2.6 & 0.57 \\
\hline
\end{tabular}


a)

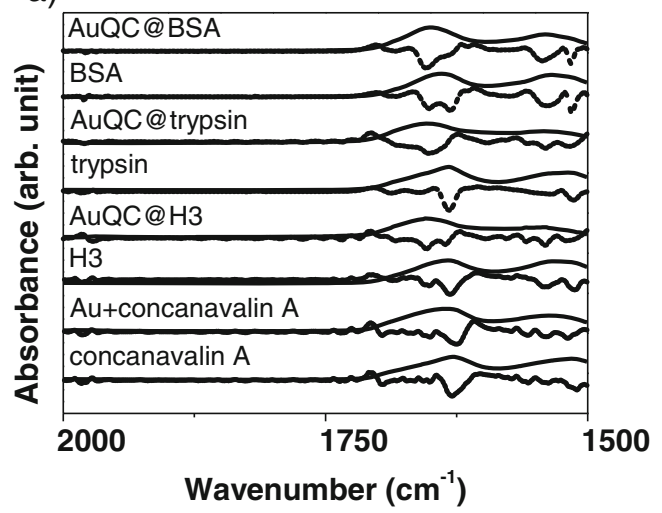

b)

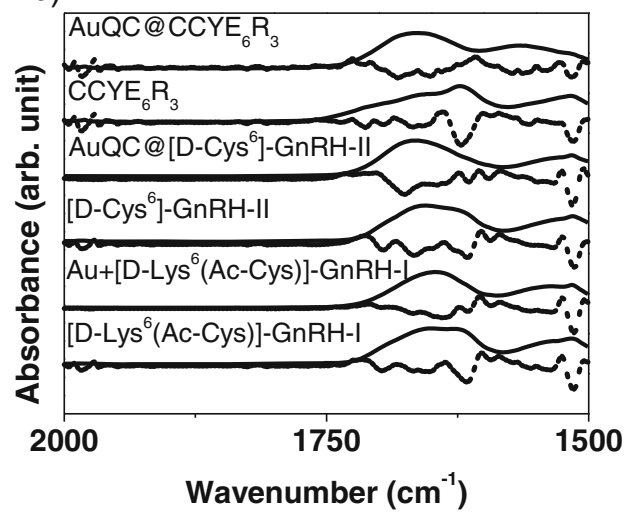

Fig. 5 FTIR-ATR spectra (solid lines) and second derivatives of the corresponding spectra (dotted lines) of native biomolecules and products of $\mathrm{HAuCl}_{4}$ reacted with a proteins and $\mathbf{b}$ peptides

the presence of gold particles, and confirmed the formation of subnanometer entities. Changes in the secondary and tertiary structures of several ACPs have been detected earlier $[14,15,17,19,34,45,46]$, which is consistent with our results.

AuQC production experiments with amino acid mixtures

In the case of amino acid mixtures, the reaction with $\mathrm{HAuCl}_{4}$ did not result in the formation of either red-emitting clusters or nanoparticles. However, a strong fluorescence band was observed at $400 \mathrm{~nm}$, which indicated the formation of dityrosine [47-49] as a result of a redox reaction between $\mathrm{Au}^{\mathrm{III}}$ and tyrosine (dityrosine was not detected if $\mathrm{HAuCl}_{4}$ was not added to the amino acid mixtures). One can find this intriguing since cysteine and methionine can form highly stable complexes with gold, limiting the reducibility of $\mathrm{Au}^{\mathrm{III}}$ in the case of tryptophan [26]. Considering these, our results suggested that tyrosine can react with gold species even if they are in complex with sulfur-containing residues, which can be an explanation for our observation that replacement of tyrosine with tryptophan can hinder the clustering efficiency of peptides. A possible reason for the inefficiency of free amino acids under our experimental conditions is that they cannot provide nucleation sites for gold species: in a proposed mechanism, formation of gold nuclei was assumed to be a crucial reaction step [34]. Cysteine-protected $\mathrm{Au}_{25}$ clusters can be prepared using an organic phase method, in which aggregation sites are established using micelles of cethyltrimethylammonium bromide [50].

\section{Conclusions}

In order to rationalize the criteria for the selection and design of bioreagents for AuQC synthesis, we performed experiments with amino acid mixtures, model peptides, and proteins, and investigated the primary structures of proteins. Studies on peptides showed that the coexistence of cysteine and tyrosine in peptides can determine if a biomolecule can potentially mediate the formation of photoluminescent, red-emitting gold clusters. These observations provide experimental evidence for earlier assumptions [3, 14]. Furthermore, our results showed that effectiveness of cysteine residues is not hindered by their disulfide-bonded state. On the other hand, their location in the peptide sequence is crucial. However, further studies with model peptides are required in order to clarify the effect of the intramolecular distance between cysteine and tyrosine residues.

We also observed that AuQCs cannot be synthesized with mixtures of free cysteine and tyrosine, which indicated that proteins and peptides do not only play a role in the complexation and reduction of gold species but also provide anchoring sites for gold nuclei [34].

Our experiments also led to the conclusion that a single cysteine residue can make a protein or peptide an efficient clustering molecule, but the concentration of the protein determines if AuQCs or Au nanoparticles are produced. We confirmed the existence of a critical protein/gold ratio $\phi_{\mathrm{c}}$, above which red-emitting clusters form. The value of $\phi_{\mathrm{c}}$, however, is in inverse relation to the number of cysteine residues in a molecule.

As a consequence of our investigation, a high variety of conjugates of photoluminescent gold clusters and proteins can be synthesized via a green synthesis route and can be designed for potential fields of application.

Acknowledgments This work was supported by the Hungarian Scientific Research Fund PD 104012, K 104385, and CNK-81056 (Hungarian Res Sci Fund and National Innovation Office), respectively. We would like to thank Professor Miklós Kubinyi for the cooperation in timeresolved photoluminescence measurements.

Open Access This article is distributed under the terms of the Creative Commons Attribution License which permits any use, distribution, and reproduction in any medium, provided the original author(s) and the source are credited. 


\section{Appendix}

Table 6 Occurrence of amino acids in proteins used for AuQC synthesis experiments; clustering activity of proteins is denoted with $+/-$ signs

\begin{tabular}{lllllllllllllllllllllllllllll}
\hline Protein & ACP & A & $\mathrm{R}$ & $\mathrm{N}$ & $\mathrm{D}$ & $\mathrm{C}$ & $\mathrm{E}$ & $\mathrm{Q}$ & $\mathrm{G}$ & $\mathrm{H}$ & $\mathrm{I}$ & $\mathrm{L}$ & $\mathrm{K}$ & $\mathrm{M}$ & $\mathrm{F}$ & $\mathrm{P}$ & $\mathrm{S}$ & $\mathrm{T}$ & $\mathrm{W}$ & $\mathrm{Y}$ & $\mathrm{V}$ \\
\hline BSA & + & 46 & 26 & 14 & 40 & 35 & 59 & 19 & 17 & 17 & 15 & 64 & 60 & 5 & 30 & 28 & 31 & 32 & 3 & 21 & 38 \\
Porcine pepsin & + & 16 & 2 & 13 & 29 & 6 & 13 & 13 & 35 & 1 & 25 & 26 & 1 & 1 & 14 & 15 & 44 & 26 & 5 & 16 & 22 \\
Porcine trypsin & + & 15 & 4 & 18 & 10 & 12 & 5 & 12 & 25 & 4 & 16 & 16 & 11 & 2 & 5 & 10 & 27 & 11 & 4 & 8 & 16 \\
Egg white lysozyme & + & 5 & 4 & 2 & 1 & 2 & 1 & 0 & 5 & 1 & 1 & 10 & 2 & 2 & 2 & 1 & 2 & 0 & 0 & 2 & 2 \\
Bovine CRABP2 & + & 6 & 8 & 7 & 6 & 3 & 16 & 3 & 8 & 0 & 10 & 10 & 12 & 4 & 5 & 4 & 7 & 13 & 3 & 2 & 11 \\
Horseradish peroxidase & + & 25 & 21 & 27 & 24 & 10 & 8 & 13 & 17 & 6 & 16 & 43 & 6 & 7 & 13 & 18 & 33 & 28 & 1 & 5 & 22 \\
Equine myoglobin & - & 15 & 2 & 2 & 8 & 0 & 13 & 6 & 15 & 11 & 9 & 19 & 17 & 3 & 7 & 4 & 5 & 7 & 2 & 2 & 7 \\
Bovine catalase & - & 38 & 32 & 33 & 37 & 4 & 26 & 22 & 35 & 24 & 18 & 37 & 28 & 11 & 31 & 38 & 27 & 23 & 6 & 21 & 36 \\
Human transferrin & + & 61 & 27 & 34 & 45 & 40 & 41 & 17 & 53 & 19 & 16 & 58 & 65 & 9 & 28 & 32 & 41 & 30 & 8 & 26 & 48 \\
Bovine lactoferrin & + & 66 & 35 & 28 & 36 & 35 & 40 & 29 & 48 & 10 & 16 & 53 & 66 & 4 & 27 & 29 & 45 & 36 & 12 & 21 & 45 \\
Bovine insulin & + & 5 & 2 & 1 & 0 & 2 & 6 & 3 & 11 & 2 & 0 & 1 & 7 & 0 & 3 & 5 & 1 & 1 & 0 & 2 & 5 \\
Bovine hyaluronidase-3 & + & 11 & 15 & 1 & 3 & 4 & 4 & 4 & 6 & 11 & 2 & 0 & 14 & 1 & 4 & 11 & 8 & 6 & 2 & 4 & 9 \\
Concanavalin A & - & 22 & 7 & 18 & 20 & 0 & 8 & 5 & 16 & 6 & 22 & 21 & 15 & 5 & 16 & 13 & 37 & 23 & 4 & 8 & 23 \\
\hline
\end{tabular}

\section{References}

1. Xavier PK, Chaudhari K, Baksi A, Pradeep T (2012) Proteinprotected luminescent noble metal quantum clusters: an emerging trend in atomic cluster nanoscience. Nano Rev 3:14767. doi:10.3402/ nano.v3i0.14767

2. Zheng J, Zhang C, Dickson RM (2004) Highly fluorescent, watersoluble, size-tunable gold quantum dots. Phys Rev Lett 93:077402-14. doi: 10.1103/PhysRevLett.93.077402

3. Wang Y, Cui Y, Zhao Y, Liu R, Sun Z, Li W, Gao X (2012) Bifunctional peptides that precisely biomineralize Au clusters and specifically stain cell nuclei. Chem Commun 48:871-873. doi:10. 1039/C1CC15926G

4. Smith AM, Hongwei D, Mohs AM, Shuming N (2008) Bioconjugated quantum dots for in vivo molecular and cellular imaging. Adv Drug Deliv Rev 60:1226-1240. doi:10.1016/j.addr.2008.03.015

5. Lin CAJ, Yang TY, Lee CH, Huang SH, Sperling RA, Zanella M, Li JK, Shen JL, Wang HH, Yeh HI, Parak WJ, Chang WH (2009) Synthesis, characterization and bioconjugation of fluorescent gold nanoclusters toward biological labeling applications. ACS Nano 3:395-401. doi:10.1021/nn800632j

6. Yuan X, Luo Z, Zhang Q, Zhang X, Zheng Y, Lee JY, Xie J (2011) Synthesis of highly fluorescent metal ( $\mathrm{Ag}, \mathrm{Au}, \mathrm{Pt}$ and $\mathrm{Cu})$ nanoclusters by electrostatically induced reversible phase transfer. ACS Nano 5:8800-8808. doi:10.1021/nn202860s

7. Muhammed MAH, Ramesh S, Sinha SS, Pal SK, Pradeep T (2008) Two distinct fluorescent quantum clusters of gold starting from metallic nanoparticles by $\mathrm{pH}$-dependent ligand etching. Nano Res 1:333-340. doi:10.1007/s12274-008-8035-2

8. Muhammed MAH, Verma PK, Pal SK, Retnakumari A, Koyakutty M, Nair S, Pradeep T (2010) Luminescent quantum clusters of gold in bulk by albumin-induced core etching of nanoparticles: metal ion sensing, metal-enhanced luminescence and biolabeling. Chem Eur J 16:10103-10112. doi:10.1002/chem. 201000841

9. Shichibu Y, Negishi Y, Tsukuda T, Teranishi T (2005) Large-scale synthesis of thiolated $\mathrm{Au}_{25}$ clusters via ligand exchange reactions of phosphine-stabilized $\mathrm{Au}_{11}$ clusters. J Am Chem Soc 127:13464 13465. doi:10.1021/ja053915s
10. Tsunoyama H, Tsukuda T (2009) Magic numbers of gold clusters stabilized by PVP. J Am Chem Soc 131:18216-18217. doi:10.1021/ ja908188f

11. Shang L, Dörlich RM, Brandholt S, Schneider R, Troillet V, Bruns M, Gerthsen D, Nienhaus GU (2011) Facile preparation of water-soluble fluorescent gold nanoclusters for cellular imaging applications. Nanoscale 3:2009-2014. doi:10.1039/C0NR00947D

12. Lin CAJ, Lee CH, Hsieh JT, Wang HH, Li JK, Shen JL, Chan WH, Yeh HI, Chang WH (2009) Synthesis of fluorescent metalluc nanoclusters toward biomedical application: recent progress and present challenges. J Med Biol Eng 29:276-283

13. Chevrier DM, Chatt A, Zhang P (2010) Properties and applications of protein-stabilized fluorescent gold nanoclusters: short review. J Nanophotonics 6:064504. doi:10.1117/1.JNP.6.064504

14. Xie J, Zheng Y, Ying JY (2009) Protein-directed synthesis of highly fluorescent gold nanoclusters. J Am Chem Soc 131:888-889. doi:10. 1021/ja806804u

15. Kawasaki H, Yoshimura K, Hagamuchi K, Arakawa R (2011) Trypsin-stabilized fluorescent gold nanocluster for sensitive and selective $\mathrm{Hg}^{2+}$ detection. Anal Sci 27:591-596. doi:10.2116/ analsci.27.591

16. Kawasaki H, Hamaguchi K, Osaka I, Arakawa R (2011) pHdependent synthesis of pepsin-mediated gold nanoclusters with blue green and red fluorescent emission. Adv Funct Mater 21:3508-3515. doi:10.1002/adfm.201100886

17. Wen F, Dong Y, Feng L, Wang S, Zhang S, Zhang X (2011) Horseradish peroxidase functionalized fluorescent gold nanoclusters for hydrogen peroxide sensing. Anal Chem 83:1193-1196. doi:10. $1021 /$ ac1031447

18. Xavier PL, Chaudhari K, Verma PK, Pal SK, Pradeep T (2010) Luminescent quantum clusters of gold in transferrin family protein, lactoferrin exhibiting FRET. Nanoscale 2:2769-2776. doi:10.1039/ c0nr00377h

19. Guével XL, Daum N, Schneider M (2011) Synthesis and characterization of human transferrin-stabilized gold nanoclusters. Nanotechnology 22:275103

20. Chen TH, Tseng WL (2012) (Lysozyme type VI)-stabilized $\mathrm{Au}_{8}$ clusters: synthesis mechanism and application for sensing of glutathione in a single drop of blood. Small 8:1912-1919. doi:10.1002/ smll.201102741 
21. Wei H, Wang Z, Yang L, Tian S, Hou C, Lu Y (2010) Lysozymestabilized gold fluorescent cluster: synthesis and application as $\mathrm{Hg}^{2+}$ sensor. Analyst 135:1406-1410. doi:10.1039/c0an00046a

22. Xie J, Zheng Y, Ying JY (2012) Highly selective and ultrasensitive detection of $\mathrm{Hg}^{2+}$ based on fluorescence quenching of $\mathrm{Au}$ nanoclusters by $\mathrm{Hg}^{2+}-\mathrm{Au}^{+}$interactions. Chem Commun 46:961963. doi:10.1039/b920748a

23. Lin YH, Tseng WL (2010) Ultrasensitive sensing of $\mathrm{Hg}^{2+}$ and $\mathrm{CH}_{3} \mathrm{Hg}^{+}$based on the fluorescence quenching of lysozyme type IVstabilized gold nanoclusters. Anal Chem 82:9194-9200. doi:10. 1021/ac101427y

24. Durgadas CV, Sharma CP, Sreenivasan K (2011) Fluorescent gold clusters as nanosensors for copper ions in live cells. Analyst 136:933-940. doi:10.1039/C0AN00424C

25. Retnakumari A, Setua S, Menon D, Ravindran P, Muhammed H, Pradeep T, Nair S, Koyakutty M (2010) Molecular-receptor-specific, non-toxic, near-infrared-emitting Au cluster-protein naoconjugates for targeted cancer imaging. Nanotechnology 21:055103. doi:10. 1088/0957-4484/21/5/055103

26. Tan YN, Lee JY, Wang DIC (2010) Uncovering the design rules for peptide synthesis of metal nanoparticles. J Am Chem Soc 132:56775686. doi:10.1021/ja907454f

27. Glišić BĐ, Rychlewska U, Djuran MI (2012) Reactions and structural characterization of gold(III) complexes with amino acids, peptides and proteins. Dalton Trans 41:6887-6901. doi:10.1039/c2dt30169e

28. Glišić BĐ, Rajković S, Stanić Z, Djuran MI (2011) A spectroscopic and electrochemical investigation of the oxidation pathway of glycylD,L-methionine and its $N$-acetyl derivative induced by gold(III). Gold Bull 44:91-98. doi:10.1007/s13404-011-0014-9

29. Harriman A (1987) Further comments on the redox potentials of tryptophan and tyrosine. J Phys Chem 91:6102-6104. doi:10.1021/ j100308a011

30. Toroz D, Corni S (2011) Peptide synthesis of gold nanoparticles: the early steps of gold reduction investigated by density functional theory. Nano Lett 11:1313-1318. doi:10.1021/n11043924

31. Shaw CF III, Schaeffer NA, Elder RC, Eisdness MK, Trooster JM, Calis GHM (1984) Bovine serum albumin-gold thiomalate complex: ${ }^{197} \mathrm{Au}$ Mössbauer, EXAFS and XANES, electrophoresis, ${ }^{35}$ S-radiotracer, and fluorescent probe competition studies. J Am Chem Soc 106:3511-3521. doi:10.1021/ja00324a19

32. Shichibu Y, Negishi Y, Tsunoyama H, Kanehara M, Teranishi T, Tsukuda T (2007) Extremely high stability of glutathione-protected $\mathrm{Au}_{25}$ clusters against core etching. Small 3:835-839. doi:10.1002/ smll.200600611

33. Negishi Y, Nobusada K, Tsukuda T (2005) Glutathione-protected gold clusters revisited: bridging the gap between gold(I)-thiolate complexes and thiolate protected gold nanocrystals. J Am Chem Soc 127:5261-5270. doi:10.1021/ja042218h

34. Chaudhari K, Xavier PL, Pradeep T (2011) Understanding the evolution of luminescent gold quantum clusters in protein templates. ACS Nano 5:8816-8827. doi:10.1021/nn202901a

35. Schmidbaur H (2000) The aurophilicity phenomenon: a decade of experimental findings, theoretical concepts and emerging applications. Gold Bull 33:3-10. doi:10.1007/BF03215477
36. Liu CL, Wu HT, Hsiao YH, Lai CW, Shih CW, Peng YK, Tang KC, Chang HW, Chien YC, Hsiao JK, Cheng JT, Chou PT (2011) Insulindirected synthesis of fluorescent gold nanoclusters: preservation of insulin bioactivity and versatility in cell imaging. Angew Chem Int Ed 50:7056-7060. doi:10.1002/anie. 201100299

37. Link S, Beevy A, FitzGerald S, El-Sayed MA, Schaaff TG, Whetten RL (2002) Visible to infrared luminescence from a 28 -atom gold cluster. J Phys Chem B 106:3410-3415. doi:10.1021/jp014259v

38. Wen X, Yu P, Toh YR, Tang J (2012) Structure-correlated dual fluorescent bands in BSA-protected $\mathrm{Au}_{25}$ nanoclusters. J Phys Chem C 116:11830-11836. doi:10.1021/jp303530h

39. Zhu M, Aikens CM, Hollander FJ, Schatz GC, Jin R (2008) Correlating the crystal structure of a thiol-protected $\mathrm{Au}_{25}$ cluster and optical properties. J Am Chem Soc 130:5883-5885. doi:10.1021/ja801173r

40. Simms GA, Padmos JD, Zhang P (2009) Structural and electronic properties of protein/thiolate-protected gold nanocluster with "staple" motif: a XAS, L-DOS and XPS study. J Chem Phys 131:214703. doi:10.1063/1.3268782

41. Devadas MS, Kim J, Sinn E, Lee D, Goodson T III, Ramakrishna G (2010) Unique ultrafast visible luminescence in monolayer-protected $\mathrm{Au}_{25}$ clusters. J Phys Chem C 114:22417-22423. doi:10.1021/ jp107033n

42. Mező G, Manea M (2010) Receptor-mediated tumor targeting based on peptide hormones. Exp Opin Drug Deliv 7:79-96. doi:10.1517/ 17425240903418410

43. Hamouda R, Bertorelle F, Rayane D, Antoine R, Broyer M, Dugourd P (2013) Glutathione capped gold $\mathrm{Au}_{\mathrm{N}}(\mathrm{SG})_{\mathrm{M}}$ clusters studied by isotope-resolved mass spectrometry. Int J Mass Spectrom 335:1-6. doi:10.1016/j.jims.2012.10.008

44. Shang L, Wang Y, Jiang J, Dong S (2007) pH-Dependent protein conformational changes in albumin:gold nanoparticle bioconjugates: a spectroscopic study. Langmuir 23:2714-2721. doi:10.1021/ la062064e

45. Mohanty JS, Xavier PL, Chaudhari K, Bootharaju MS, Goswami N, Pal sK, Pradeep T (2012) Luminescent, bimetallic AuAg alloy quantum clusters in protein templates. Nanoscale 4:4255-4262. doi:10. 1039/C2NR30729D

46. Baksi A, Xavier PL, Chaudhari K, Goswami N, Pal SK, Pradeep T (2013) Protein-encapsulated gold cluster aggregates: the case of lysozyme. Nanoscale 5:2009-2016. doi:10.1039/C2NR33180B

47. Harms GS, Pauls SW, Hedstrom JF, Johnson CK (1997) Fluorescence and rotational dynamics of dityrosine. J Fluoresc 7:283-292. doi:10.1023/A:1022525909128

48. Giulivi C, Traaseth NJ, Davies KJA (2003) Tyrosine oxidation products: analysis and biological relevance. Amino Acids 25:227-232. doi:10.1007/s00726-003-0013-0

49. Si S, Bhattacharjee RR, Banerjee A, Mandal TK (2006) A mechanistic and kinetic study of the formation of metal nanoparticles by using synthetic tyrosine-based oligopeptides. Chem Eur J 12:12561265. doi:10.1002/chem.200500834

50. Yuan X, Yu Y, Yao Q, Zhang Q, Xie J (2012) Fast synthesis of thiolated $\mathrm{Au}_{25}$ nanoclusters via protection-deprotection method. $\mathrm{J}$ Phys Chem Lett 3:2310-2314. doi:10.1021/jz300960b 